\title{
The Role of Suriname in Haitian Migration to French Guiana: Identities on the Move and Border Crossings
}

\author{
Maud Laëthier
}

Caribbean societies are defined by a historical heritage marked by the colonial relationship and by slavery, and by the dynamic character of the social and cultural constructions that emerged from these. Yet, today, their designation as 'creole worlds' underlines a diversity or a 'new' unity. ${ }^{1}$ The migratory movements that have affected them for about thirty years have altered their sociodemographic configurations and have contributed to the emergence of new social and political forms. Understanding these migratory dynamics is of the utmost importance for revealing social re-compositions, new forms of political mobilisations, and identity redefinitions.

In this context, Haiti is one of the countries, or even the country, from where emigration is most significant. Haitians are currently among the most numerous migrants in several Caribbean countries and especially in the French Overseas Territories. This is the case in Guadeloupe, St Martin, and in French Guiana where Haitians constitute $30 \%$ to $50 \%$ of the immigrant population. ${ }^{2}$ Migrants are also present in Martinique and Suriname, both of which function as points of entry to French Guiana.

This chapter deals with the migratory processes from Haiti to French Guiana. Indeed, migration sometimes reveals itself as multiple and/or successive experiences of mobility that integrate, connect and prioritise various places. To investigate migrations is indeed to talk about movements in space, between the places of departure and the places of arrival, but it is also about

1 In this usage, which is common in the francophone literature, 'creole world' refers to notions of 'hybridity' and cultural mixing in society (see Jolivet 1982, 1997).

2 Guadeloupe and French Guiana are the French Overseas Departments where the presence of migrants is the most significant. Haitians constitute respectively $44 \%$ and $30 \%$ of the migrant population of these two regions. In St Martin, migrants represent more than $30 \%$ of the population, half of which come from Haiti (see INSEE 2006a et b).

(C) MAUD LAËTHIER, 2015 | DOI 10.1163/9789004280120_011

This is an open access chapter distributed under the terms of the Creative Commons Attribution-

Noncommercial 3.o Unported (CC-BY-NC 3.0) License. 
grasping the ease or the difficulties of travelling and when relevant, taking into account the places passed through. In this chapter I will consider how the establishment and the functioning of Haitian migration networks to French Guiana reveal the role played by Suriname in circulatory migration. ${ }^{3}$ However, to talk about migrations is also to consider the social organisation of a new norm. New forms of socialisation and social transformations are also at the heart of the question. The viewpoint developed here will thus focus on two aspects: the forms of insertion of the new migrants and the corresponding identity constructions.

Our analysis proposes three steps that will lead us from Haiti to Suriname and French Guiana. The first step aims at understanding the logic at the basis of the mobilities from Haiti. The second step will show how these mobilities develop in Suriname through the migrants' organisational modes. The multiplicity of trajectories, the gradual construction of the paths and their reconstructions will show how Suriname has become a place of transit and also of more or less long-term settlement. Moreover, we shall discover how this country is simultaneously the centre of cross-border mobilities. Thus, the last part of the discussion will position us on the Guianese side of the border. The migrants' insertion into the economic and social situation of the west of French Guiana shall be enlightened by a discussion of the relationships that have developed between Haitians and members of the major social groups that they encounter in present-day French Guiana. We shall also consider the identity constructions that shape individual and collective memory in the migrant condition.

My aim is to report the facts of mobility and to work out how they link up in the articulation, at different levels, of the Haitian migrant experience. From this double perspective we shall show how multiple networks and territories invested by migration trajectories come to light through an approach that reinterrogates the alternative between settlement and circulation and between

3 The data presented here were collected from surveys carried out in 2008 and 2009 in French Guiana and Suriname within the ANR research project: "Circulatory migrations dynamics and cross-borders mobilities between French Guiana, Suriname, Brazil, Guyana and Haiti” (IRD/ AIRD). These data complement other data collected in French Guiana and Haiti since 2001. Part of the survey results were presented at the international symposium "Transit migration in Africa. Local and global dynamics, political management and actors' experiences" held in December 2009 at Nice Sophia Antipolis University, see M. Laëthier (2011b). The terms by which the routes through Paramaribo are experienced are based on this first analysis. 
the individual and the collective in the act of migration. The social and territorial universes crossed in Suriname and in French Guiana will bring us onto the path of what could be called 'mobility fields', produced by the appropriation of territorial practices and the creation of representations.

\section{Leaving Haiti for French Guiana}

In Haiti, as well as in many other countries, emigration has been, for several decades, a known reality, practiced and fantasised. However, Haitian emigration takes on a character of its own: few countries in the history of what can be called, after Roger Bastide ([1967] 1996), the 'Black Americas', have experienced such poverty and such political turmoil, suffered from such an acute and known marginalisation and undergone such a massive emigration. Indeed, despite the haziness of official estimates, Haitians may number more than two million living outside of Haiti compared to a local population of about ten million (IHSI 2003, 2008).

Vwayaje 'to travel' is, in the Haitian context, the word used to talk about migration. To 'travel' means to migrate. To migrate is chèche lavi 'to seek a life' which, as a leitmotiv, punctuates the discourses on the desire to migrate, as if all the reasons for departure were contained in it. 'To travel' is first of all 'to seek a life'. The idea, that by crossing borders one can achieve fulfilment, is very vivid and foreign countries appear as a break away from what is known. This is illustrated by the expressions peyi bondye ‘God's country' or peyi beni 'blessed country' to refer to them.

One of the central points contained in the expression 'to seek a life' is first the possibility of another social experience. A condition that contains in itself another principle, another notion, namely that of equality. An equality of condition. Which equality is it about? Social equality? Economic equality? Political equality? 'To travel' with its imagination and representations does not separate these dimensions. The equality contained in 'to seek a life' is this possibility of resembling 'others'. To be on the 'other side'-abroad, is the possibility to experience this fundamental quality of fellow beings without it being questioned. It is the possibility of not being stigmatised because of a social condition considered inferior within the 'Haitian system'. The belief is shared that 'to travel' means an end to persistent unfair conditions. But it does not constitute an escape from a social hierarchy and it is not a search for formal equality that would derive from the refusal of the existence of differences of functional positions within the social body. In short, it is not so much to think 
of oneself as equal but the possibility of being in a context that acknowledges one's equally. ${ }^{4}$

Yet, 'to travel' also refers to having succeeded in leaving. I will not question, within this contribution, the migratory process and the stories related to it. Nevertheless, I have to recall certain facts that I analysed elsewhere and that are necessary to bear in mind (see Laëthier 2011a), namely I will briefly discuss the way the departures are organised and the journeys conducted since they make the arrival in Suriname and French Guiana meaningful.

3 Networks, Routes, and Migration Projects

Haitian migration to France was taking place as early as the 1950s, but from the 1970s onwards it extended beyond the hexagonal borders. New migratory flows linked to new migrants, from rural areas and not belonging to the highest social strata, appeared and from then on the French Departments of America were included in the destinations. However, the highest number of migrants are found in French Guiana.

The first migrants to arrive in French Guiana left from the southern departments of Haiti, namely the South, Nippes and Grande Anse. At the end of the 1960 s, there were only a few hundred people but, gradually, networks emerged based on family and on relationships in their villages of origin (relations I call inter-knowledge relationships). By the end of the 1970s, the number of arrivals had risen. It may be recalled that within the explanations of migratory movements, an intermediate scale operates between the macro-economic and the micro-sociological level (Faist 1997) that shows the importance of networks and families in the decision and the realisation of migration. In the case of Haitian migration, socio-economic situation and individual aspirations are decisive elements for mobility but they are not sufficient conditions for its continuation. At their crossing, mobility has indeed to be related to the existence of the networks that shape it: migration is first and foremost a part of family strategies. The migration's unity resides in the networks based on inter-knowledge relationships (Laëthier 2011a).

4 This topic proposes the analysis of social imaginaries and migratory imageries, as a universe of representations, in which the tension is expressed between a quest for equality at an individual level and the egalitarian ideal as a principle part of society and from which the relationships of its members fuel. The article by D. Vidal (2009) on the way this issue arises within the identity constructions of female domestic workers in Rio de Janeiro is in this regard particularly enlightening. 
Since 1980, however, institutional barriers have thwarted movement and redirected the routes. Indeed, until that time, an entry visa to French Guiana was not compulsory. A stricter immigration policy led to a decrease in the number of arrivals. This trend was, however, temporary as migration networks through neighbouring Suriname started to take shape. New routes and migratory patterns emerged from the countryside of southern Haiti, where most of the migrants come from, through Port-au-Prince, to Paramaribo that do articulate, however, with the previously established networks.

The new 'Surinamese route' is followed by those who cannot obtain a passport, visa or any of a number of other documents, for example, a written invitation by a relative who is already lawfully residing in French Guiana. They then resort to migration networks, also named filon 'vein' in Creole. Of course, there is another more legal filon for entry into French Guiana: the migrant may buy a short-term visa mentioning the 'French Departments of the Americas' and then simply overstay. But the cost is very high. A cheaper alternative is the 'Surinamese route' with the rakètè, the smugglers. These smugglers work with 'agencies' (ajans), networks of intermediaries who are distributed along the route. In the rural villages of southern Haiti it is not uncommon to encounter agents who work for the smugglers and a lot of people know them or their agencies. However, most of the 'business' is negotiated and organised from Portau-Prince. The Surinamese embassy is the place where one has to obtain the entry permit to Suriname issued with the same name as the one mentioned on the passport one is travelling with. But the efficiency of the network depends on the continuum of intermediaries. Thus, in Paramaribo, the taxi driver waiting at the airport enters the scene, then the hostel keeper where the migrants stay. For those whose journey is organised as far as French Guiana, the taxi to Albina and then the boatman enabling the crossing of the Marowijne all play their part. The intermediaries and beneficiaries of the illegal networks are numerous.

We specified above that from an institutional and normative point of view, the emergence of Suriname in circulatory migration originating in Haiti is linked to obtaining an entry permit. This is still the case although changes are taking place. Entry permit requests are not often granted and so migratory routes are reoriented. Faced with the impossibility of getting a permit or of using one obtained by another person, some people travel through Peru and then Brazil to enter French Guiana. New migration networks and trajectories emerge and other borders are crossed. While the rate required by the smugglers is, for the time being, the same as the one imposed on the 'Surinamese route'since 2000 the price has been between us $\$ 2500$ and $\$ 3000$ - the conditions of these new routes are, however, quite different. It is widely acknowledged that 
to travel along these routes means to travel in bad conditions, so acutely long, difficult, and clandestine is this journey. For this reason, it is generally known that in order to travel to French Guiana, it is better to go through Suriname.

This raises another theme I shall return to later: the migration project. Let us consider briefly the networks supporting the migratory movement. We mentioned that Haitian immigration, originally composed of people who arrived from the 1960 s onward, was maintained by family and inter-knowledge networks. These networks have acquired a certain 'autonomy' and they have an influence on the costs of migration, the maintenance of links and the migrants' choice of networks. ${ }^{5}$ Thus, some migrants explain how the decision to leave was taken hastily; certainly the individual project to leave the country had already been expressed but its realisation was made possible by the family having already settled 'on the other side'; 'to seek a life' is not only 'to seek one's life.' Furthermore, networks allow universes of norms to be crossed; they represent a valuable support for the newcomers who can benefit from emotional or material support, and sometimes from possibilities of regularisation. We shall also consider how migrants adjust to economic demand and have access to some socio-economic spheres, this access being determined by the presence of compatriots.

However, if the inter-knowledge networks definitely became migratory resources, when the act of migrating is a part of family strategies, including both migrants-to-be and non-migrants, this must not cause us to lose sight of the fact that mobility is an initiative too. Migration is determined by collective strategies and from this point of view the group controls the individual but the individual's choice also directs the migratory practice. Thus the call to migrate has the coherence and strength of social logic but it also possesses the plasticity of a creation; a continued process of creation in the series of steps by which it is defined. Indeed we have to try to achieve an analysis of mobility that takes into account the modality of the social links that shape it, while allowing the individualising logic, applied in the timescales of mobility. This conversation between collective choice and individual orientation makes the migration project feed on the migratory act. We thus follow the perspective put forth by E. Ma Mung (2009) that shows how the notion of 'migration project' enlightened by the notion of 'migratory process of creation' allows us to consider jointly 'know-how' and 'can-do' as two dimensions of autonomy in the migratory processes-considering that we accept the use of the theme of

5 See the study by D.T. Gurak and F. Caces (1992), where they put forward two main uses of the networks: adaptation and selection. 
autonomy in the analysis of migrations. ${ }^{6}$ The notions of 'migration project' and 'migratory creation' articulate, thus organising what we shall call after E. Ma Mung (2009: 27), the 'external conditions' and the 'interior inclinations'. In this respect, the transits through Paramaribo show how the choice and the implementation of resources are subject to continuous development. Migration is not only pre-organised travel (Cohen 1997; Ellis et al. 1996; Fawcett 1989; Hammar et al. 1997; Kritz et al. 1992), it is also a more conjunctural construction that nevertheless articulates 'know-how' and 'can-do'. The analysis is thus directed to the identification of migrants as subjects (individual and/ or collective) and actors operating on a context and transforming it to their own advantage. 'Passing through' and 'being in transit' then appear to be conditions that prompt analysis questioning the phenomena of mobility as much in the intermingling of their collective and individual dimensions as through the shift from and/or the combination of one type of migration with another.

\section{$4 \quad$ Along the Road: Suriname}

We shall focus here on how the different ways of passing through affects the migratory experience and the links with networks on the French Guianese side. In this context the emergence of Suriname, and especially of Paramaribo, in circulatory migration ${ }^{7}$ raises a first question concerning the fact that Paramaribo is seen as a transit area and Haitians as transit migrants.

Unless they come from Venezuela by road, Haitians leaving their country can enter Suriname only by arriving at the international airport of Paramaribo and therefore it is necessary to be in possession of a visa. It is thus with a valid temporary visa that Haitian migrants enter Surinamese territory. However, as mentioned above, the emergence of new 'routes' indicates that Suriname is undertaking practices of normalisation and a stricter policy on issuing visas and carrying out controls. Yet, at the same time, to regularise a stay after having entered Surinamese territory by registering as a foreign resident is still a rather

6 On the place awarded to the migration project as a notion within the analysis of migrations, see, as indicated by E. Ma Mung, the works by Paul-André Rosental (1999) and Florence Boyer (2005a, 2005b).

7 Circulatory migration means mobilities of goods, people and information that constitute a link between spaces were migrants live. Circulatory migration is equivalent to the places linked by migratory networks as they are defined by Gurak and Caces (1992) or Faist (1997). See Dorai et al. (1998) for a discussion of this notion. 
simple administrative procedure in comparison to what we know in France. ${ }^{8}$ Thus, some migrants in French Guiana apply for a residence card in Suriname so that they can then be sent back to there rather than all the way to Haiti, in the case of deportation by French authorities. This administrative frame allows Suriname to be labelled an 'area of transit', but one has to let go of any strict notion of transit as linear mobility, and its experience as such by the migrants involved. Paramaribo can be a stepping stone or it can become a place for a long-term, or temporary, sometimes unplanned settlement, or it may also be a place to where those who have successfully migrated to French Guiana may, if they wish, return (see case discussion below). The facts of mobility comprise a wide range of experiences, the heterogeneity of which have to be taken into consideration.

When functioning as a stopover, the city is a passing through or relay point that migrants quickly leave. Within a few days after their arrival, they leave the hostel, managed by fellow-countrymen, where the smuggler gathered them. However, it is not uncommon to encounter migrants left out by smugglers with neither money nor documents. These migrants came with what is called the 'rubbing off' (dekolaj); the passports they travel with are real, with real entry permits, but with the photograph of the traveller stuck over that of the former owner of the passport, without the original name changed. The illegality of this practice appears relative: one travels under a false identity but with authentic documents and entry permit. However, if migrants have given their own passport beforehand to the 'agency' and the smuggler does not give them back to them, migrants are left without any proof of identity. Such document fraud is common, even when smugglers, aware that this type of story can only play against them, accept a 'contractual' requirement to return the papers as well as payment, in instalments (often in two steps), of the total amount to the migrant or by one of his or her relatives in Suriname or French Guiana. In Paramaribo, the persons deprived of their savings and with no identity papers then rely on the solidarity of their compatriots. Among them, some are waiting for an amount from their relatives settled in French Guiana when the 'travel' was planned via Paramaribo, others join their family there, and yet others were formerly settled. It is through these persons that the newcomers 'learn about' the city. But 'city' is not the appropriate word. Admittedly, foto (Sranantongo: 'city') is the word used to refer to Paramaribo and its outskirts, but even though some live in the city centre near the Central Market, most of the migrants live outside. The areas to the West of Paramaribo, between

8 In addition to the payment of a tax in order to be granted a residence card for the Surinamese territory, the presence of family members is compulsory. 
Kwattaweg (Landsboerderij) and Nieuw Weergevondenweg (Tammenga/ Bomaweg) to Jarikaba and the town of Uitkijk, are the places where Haitians live. Some have been there for a long time, others have just arrived and others are about to leave. Underlying these modalities that give meaning to circulation and migratory experiences, these places are designated by the migrant themselves as 'Haitian fiefdoms'. One gets to know the pastors from several churches, the smugglers' houses, the shops where Haitian foodstuffs and cooking products can be found. Moreover migrants also get in contact with compatriots who may help to find informal and often short term work. The economic logic is indeed emphasised by socio-cultural factors while the inhabited areas are closely linked to the activities carried out. Precisely, the newcomers rely on those migrants who have settled and who play an important role in the circulation of information and in employment. Those who are considered to be settled are the compatriots who arrived in Suriname during the first years after the country's independence (late 1970s) when a workers' migration was organised. In relation to this point, we wish to underline that the routes of the settled migrants also take on their full meaning within the links they established on the other side of the border, in French Guiana. Let us quote Okès' case, about fifty years of age, from Croix des Bouquets and who arrived in Paramaribo in 1977 with a work contract. He explains:

They didn't pay, so we decided to stop working in the cane fields. We broke the contract. At the beginning, we wanted to go back home, to our country. We thought we had nothing to do here. And then... Well, we stayed. I worked elsewhere, I did farming. Life was good.

But, as early as 1983 , Okès made several journeys to French Guiana:

I knew that on the other side, there were many Haitians. They passed through here. But then the compatriots, those who came at the same time as me, they didn't want to stay either. All of them were going there, to the country of France with the others. Well... I said to myself: "why not me?

In 1986, Okès joins compatriots settled in Cayenne where he then meets his wife-to-be. She is also Haitian. Soon, a first child is born, then a second. Okès regularises his situation; he obtains a residence permit thanks to a legal job and the fact that he has become a father; his wife being herself in regular employment. However, in 1995, Okès decides to come back to Suriname for a longer period: 
Yes, my wife and children stayed. French Guiana is better for them but not for me... Actually I never wanted to stay permanently. A friend from my village was keeping my house and fields here. It's complicated over there. Here Haitians are left alone. Yes, of course, I often go to Guiana and, you know, I've got papers, I'm no 'illegal Haitian' ... My wife and children are there and I also go there to sell. Oh yes, it's interesting over there for selling. I farm, I carry my products and I sell in French Guiana. I sell as far as Cayenne. I know who to sell to. But to live, I'm fine here. (Translated from Haitian Creole, Paramaribo, 2009).

Okès lives close to Uitkijk, where he built his house. His farmland is nearby, on land that he cleared himself. He sometimes employs Guyanese people, or 'English', 9 and a lot of compatriots who are passing through Suriname on their way to French Guiana.

Many other examples could be given, showing that like Okès, routes are not linear, and that as we will see, settling and passing through, become meaningful in the links with French Guiana. For the settled migrants and the newcomers the migratory routes are redefining. They are redefining at the scale of the individual and of the group; kinship groups and also 'fellow' groups within which the relationships are often based on shared regional origins (which I refer to here as 'inter-knowledge relationships'). However, if the origin of the Haitian departmental scale is similar to the one observed in French Guiana, on a communal scale, differences appear for the migrants who arrived during the past decade. Thus, for the department of the South in Haiti, the migrants coming from Saint-Louis du Sud, from the Cayes or from Fonds-des-Blancs and from the surrounding communal 'sections' 10 are more numerous. An increasing number of migrants from Léogane, Port-au-Prince, Cabaret or from Croix des Bouquets, in the Western department has also been observed. However, whether they be individuals, kinship groups or fellows' groups, the routes and mobilities also articulate with other elements of contexts, and primarily to

$9 \quad$ Haitians, like other residents of French Guiana, refer to citizens of Guyana as 'English'. Note, however, that in French Guiana this naming has long been used to designate all the inhabitants of the former English colonies such as the Saint Lucians or the Dominicans (Jolivet 1982).

10 Most of the places migrants principally come from so far are: Aquin, Vieux-Bourg of Aquin, Asile, Fond-des-Nègres, Bouzi, Morisseau, in the Southern department and the Nippes department. Please note that the 'communal section', formerly called 'rural section' is the smallest entity of the administrative division of the Haitian territory. It refers to a group of several 'houses' composing micro-territories where people, who are generally related, live. 
economic conditions. From this point of view, the strategies and the singularities revealed are as social as they are spatial.

Selling agricultural products and textiles is the first activity of migrants. Carried out within a family system, these activities involve both the long-term 'settled' people and those whose migration project includes an impending departure. These activities are informal, they are not very lucrative but the possibility to practice them as one did in Haiti, is often put forward as a reason to practice them, as we shall see. However, numerous migrants also work in sugarcane or banana fields, as in the area of Jarikaba where the settlements are linked to a nearby factory. At the beginning of the 2000s, the factory's closing prompted an exodus to French Guiana. For men, temporary employment as construction workers or taxi drivers are among the other options. Women work less often as domestic servants than they do in French Guiana. According to what is said here by the Guianese women, this kind of work is the 'English' women's field, not that of Haitian women. "Here, Haitians are not the lowest ones" is often repeated. The Haitian vendor activities are seen as being practiced 'freely' and without hierarchical constraints. They are not in the situation of those not envied, but it is nevertheless asserted that some work carried out here would not have been done in Haiti for fear of being mocked. These misgivings [about the type of work one is forced to do] also inject meaning into the processes of identity construction, in the differentiation migrants develop with regard to groups they live among. In Paramaribo, Haitians sell their products to Creoles and Hindustanis and sometimes work on fields owned by Javanese, with whom they also trade. Exchanges thus take place in Sranantongo as in the case of exchanges with people from Guyana. Even though it is necessary to know Sranantongo, most Haitian migrants only have a limited knowledge of that language. At times it happens that Haitians who were born in Suriname and attended school there or those who have been there since the 196os, start off conversations in Dutch if they do not know their interlocutor. These cases are, however, not frequent for two reasons. First, these interactions among men usually take place in Sranantongo. Second, and probably most importantly, if the interlocutor is not interested in maintaining a relationship characterised by social distance, the conversation will soon be continued in Haitian Creole. Essentially, interactions among Haitians generally take place in Haitian Creole. It is often the sole language spoken by them, even by those who have already spent a considerable amount of time living in Suriname. Haitians who live 
outside of the centre of Paramaribo typically know Sranantongo. It is the language that they use for most of their exchanges, including those that involve commercial activities. Yet, the previous example suggested that activities related to trading are also carried out within a frame of adaptive strategies developed by migrants from Paramaribo to Saint-Laurent-du-Maroni and sometimes Cayenne. In addition to the trading of agricultural products, people also re-sell goods bought or transformed/manufactured in Suriname. Let us consider the example of those women, 'resellers' (revandez) or 'saleswomen' (machann) as they call themselves. These "resellers" travel to French Guiana to sell their goods and they often involve other compatriots who help them and travel with them. Clothes, shoes or cosmetics are then resold at local markets or in door-to-door trade to compatriots. Other women, whose administrative and financial situation allows it, trade on a larger scale: they go from Paramaribo to Caracas and sometimes from Caracas to Miami going through Port-au-Prince. These retailers carry out cross-border trade based on a commercial system that again replicates strategies known in Haiti. Some 'resellers' do not live in Suriname, rather they live in western French Guiana or in Cayenne. Once or twice a month these 'resellers' go to Paramaribo to acquire their products." Going back and forth rarely lasts more than two days. Each one of them knows the 'taxi' which will bring her to Saint-Laurent, including the 'Bosh'- the word used to designate a person of Businenge origin, see below-boatman who will safely transfer her and her products across the Maroni and the other boatman who, on the way back, will carry the goods across, slightly detouring to avoid possible controls during which one's products may be seized (see also de Theije, this volume). ${ }^{12}$ In discussions about language, the newcomers say that they speak Takitaki. Those who live in Suriname use Sranantongo and generally refer to it as speaking Sranan. At times it happens that they use the term Ndyuka, Bosh or even Takitaki, if they know that term. In western French Guiana, Takitaki is the term used by Haitians to refer to the language they need to know to some extent for exchanges with people of Businenge origin. In fact, Sranantongo is often mixed up with what is called Takitaki and Haitians living in Suriname are perceived as being more fluent in this language. However, Takitaki is also used to designate not only what is referred to as Sranantongo in the literature, but also what is locally referred to as 'the language of the river'

11 These migrant women use the argument of the absence of hierarchy related to their 'independence'. Cf M. Laëthier (2011a).

12 With police controls more frequent, women who live in a regularised situation in French Guiana know that they had better possess a visa. Depending on the type of short-term visa, one or several entries into Surinamese territory is allowed. 
and the varieties of Nengee. It is seen as 'the language of the Bosh', 'the language of the Saramaka' and 'the language of the Ndyuka'. This is well documented by scholars working in French Guiana (Collectif 2000; see Migge and Léglise 2013 for an analysis). A reseller who does not speak Takitaki as she calls it will not go out to sell her merchandise without a Haitian woman who considers herself competent in that language. At times both sets of interlocutors-the Haitian and the Businenge person-interact in French Guianese Creole if both of them speak it. There are also boatmen or sellers of Businenge origin who know some words in Haitian and thus communicate with Haitians by mixing French Guianese Creole and Haitian. However, in practice, what constitutes the border is not just the Marowijne/Maroni river, but also the road leading from Albina, the border town on the Surinamese side, to Paramaribo where police control the space. In this case, the use of the word border does not so much refer directly to a property of the State, but rather to the practices of some of its agents, the policemen, and the representations migrants have of them. It appears that the road is not a border or an obstacle but a space for negotiation which is underscored by the existence of corruption. By their economic activities, Haitians become cross-border migrants, defining, in their way, a 'local transnational space'.

But, regarding economic situation, administrative status, and social advantages, the situation experienced in Suriname is often compared to what is known - and expected—of French Guiana. Let us consider the case of this man.

Here, it's true you can settle there and sell your products. In Guiana, it's not easy like this. But with the Euro, you earn, here, you manage but you don't earn. And there are other problems. Suriname has no social security system and little is done for Haitians. Now people think Haitians are rich; they plant vegetables and all they can, then, they sell, so they are rich. The Coolies don't help us. If you are sick, you go to the hospital and you have to spend all your money. Otherwise you can die, they don't take care of you. In Guiana, it is different, with the French. On the other side [in French Guiana], the Euro is better than the Surinamese currency and you can be cared for. It's better. Well..., it's true there is no work, you need papers. Without papers, you don't live. Here you manage, even if you don't have papers. (Translated from Haitian Creole, Paramaribo, 2009)

Such narratives are frequently found. Representations and practices attached to the living conditions in Suriname and in French Guiana produce contrasting images that are also ambivalent. From the Surinamese viewpoint, it is the 
economic and social issue that turns migrants into 'leavers'. Seen from French Guiana, it is the issue of papers. In western French Guiana, the papers' issue takes on a singular meaning within the relationship established with other migrants and especially with the Maroon groups, even if it is a 'common' issue among all the migrants. Having papers means, then, resources and uses, and constitutes trademarks. From this point of view, being migrant is stated differently in French Guiana than in Paramaribo. The scattering within the two national spaces takes on its meaning according to the differences of regulations, economic potentialities or social advantages of both countries. But the perceptions of these differences and the practices they create also depend on the symbolic and imaginary value attributed to the two national spaces. For those who arrive, or who are, in French Guiana, the symbolic value attributed to French Guiana as a 'country of France' enters within the identity definitions Haitians construct of themselves; it gives another meaning to their mobility. They have different expectations when going to Paramaribo or to French Guiana, in short, because of their perceptions of France, they dream of better social success in French Guiana.

\section{From Suriname to the Guianese West}

In French Guiana, Haitians principally settle in Cayenne. Their presence is more important and older than in the western part of the department where the first numerically significant arrivals date back to the beginning of the 1990s. ${ }^{13}$ However, since this period, migrants continue to settle in the towns of Saint-Laurent-du-Maroni and Mana, and there are relatively large numbers of migrants there from the early 200os. Among them, some obtained a residence permit but a lot of them have not yet engaged with the administrative system in order to regularise their situation. And, contrary to general belief, this not only affects those newly arrived. 'Illegal' migrants only rarely move to other parts of the department. The main reason for this is the presence of a permanent gendarmerie roadblock at Iracoubo, a village along the only road to Cayenne, whose purpose is to control the flow of migrants and smugglers from the western to the eastern part of French Guiana. The border is, again, not to be considered as a line geographically separating two states but as a limit separating territories within a single national space; a limit that shapes as

13 The conflict in Suriname (1986-1992) only partly disturbed migration networks as the villages of Galibi and Awala-Yalimapo, at the extreme North-West of Suriname and of French Guiana became a new 'route'. 
much the identity compositions as the modes of recognition among compatriots (Laëthier 2011b).

\section{$7 \quad$ Being a Migrant and Circulating}

Having arrived in western French Guiana, migrants' economic integration takes place in a certain socio-spatial continuity with Suriname. Unlike what happens in Cayenne, migrants are less likely to be confined to jobs in the domestic services sector involving activities such as cleaning and building. Most people work in the agricultural sector and in trading. They grow agricultural products and sell them to French Guianese Creoles, Chinese and especially to people of Hmong origin. ${ }^{14}$ Family-run slash-and-burn farming usually takes place in fields owned by French Guianese Creoles. In some cases Haitians are tenant farmers or sharecroppers. In other cases, migrants' farm land for which they do not have titles belongs to the state. Haitians living in the municipality of SaintLaurent-du-Maroni who have regularised their status try to legalise their occupancy by applying for a licence for agricultural development. Some migrants occasionally return to Suriname to work after meeting compatriots in French Guiana who are settled in Suriname and who will inform them of work opportunities as they arise. The following example illustrates this point.

Estève is a 38 years old man. Originally from Saint-Louis-du-Sud, Estève left Haiti in 1995. He stayed for five years in Suriname after coming with the help of 'agencies'. His 'travel' was not planned as far as French Guiana, but as he wanted to settle there, he went there several times. After two deportations to the border because he had no residence permit, Estève settled in the area of Jarikaba. This is where his wife Elvesia joined him in 1999. The year after, Elvesia's father, who lives in Mana and has a residence permit, helped the couple to come to French Guiana. However, Elvesia was not able to get a residence permit based on family reunification procedure. As for Estève, he applied several times for regularisation; all his applications were rejected. The couple and their two children, born and going to school in Mana live along CD 8 in a wooden

14 From 1977 onwards, the French government organised the settlement of the Hmongs, refugees from Laos, in the villages of Cacao and Javouhey. Specialised for a long time in vegetable farming, the Hmongs have been supplying Cayenne's market since their arrival. Nowadays Hmong have shifted from growing to selling agricultural products, with Haitians taking over the farming niche. 
house without running water and electricity that was built by Estève. The land belongs to a French Guianese Creole man who lives in Cayenne. When Estève does not have enough cash to pay the rent, he pays in agricultural products. His slash-and-burn fields are behind his house and he goes there every day. But Estève sometimes goes to Foto too for a 'job' obtained through one of his compatriots.

There are many Haitians living along $\mathrm{CD} 8^{15}$ in similar conditions to what Estève and his family experience; they go to Suriname from time to time for work but continue to live permanently in the French region where their children attend school. It is not unusual to visit a family and to be told: "So-and-so went to Suriname. You'll find him next week". We will return to this issue when we discuss how Haitians in this part of French Guiana construct their identity.

Apart from trips for work and trading, Haitians from French Guiana also go to Paramaribo for other reasons. Regular migrants fly to Haiti or the United States of America via Paramaribo's airport as tickets are cheaper than from French Guiana. Irregular migrants also travel via Paramaribo to Haiti when the need arises, for example, in order to attend a funeral or to organise one for a relative, or to be treated by stronger 'magic'.

There are also migrants, who after having settled in western French Guiana choose to go back and settle in Suriname. Okès' example is a good illustration of this case. However, few conceive of such a return as permanent. If they are offered a job or are able to obtain residency papers for French Guiana, they usually return there. Indeed, hope is permanently sustained in this field, or at least people try to convince themselves by convincing their interlocutor, as though otherwise the legitimacy of their presence is at stake. For these migrants, men more than women, ${ }^{16}$ travel frequently; they go back and forth repeatedly and thus a certain familiarity with the places and countrymen develops.

Each migration project is a "strategic, pragmatic and contextual procedure" as Boyer (2005b: 52) reminds us, after J. Lévy and M. Lussault (2003). They underline the long duration of a migration project that contributes to its permanent redefinition. The migration project is individual and part of a collective experience of time (of a given time period), it adapts several times

15 From Mana, the departmental road called CD 8 leads to Cayenne and CD 9 leads to SaintLaurent-du-Maroni. At the time of the civil war in Suriname, two 'refugee' camps were opened along this road for the PPDS or Persons Provisionally Displaced from Suriname. The camps were officially closed in 1992, but many former PPDS stayed or settled nearby. Few Haitians live along the CD 9.

16 With the exception of the 'resellers' mentioned above. 
to the context. It involves several scales where migratory 'know-how' and 'can-do' (re)combine. 'External conditions' and 'interior dispositions', to reuse the terms by E. Ma Mung (2009), combine together, creating a sort of (what I would call) migratory capital that evolves.

From this point of view, the data suggest that each migrant's experience is to a certain extent unique and gives rise to new types of contact and non-linear mobilities. Whether they are migrants settled in Suriname, migrants planning to go to French Guiana, migrants coming from Suriname and currently living in French Guiana, with or without a legal administrative status, or migrants who return to Suriname after a shorter or longer stint in French Guiana, itineraries are made up of multiple mobilities that do not fit into a single category of mobility.

Migrants' economic integration often leads to a certain degree of homogenisation. But the collective subject that is established in interaction with other groups, develops mobilities that produce many experiences opening onto a non-static situation. Between constraints and initiatives, this double movement shows how migrants organise the 'external conditions'. Thus, in the west of French Guiana, migrants construct 'mobility fields' (Laëthier 2011b), where through forms of territorialisation, mixing mobility and anchoring, the border area is extended and diverted. International and cross-border migration thus combine within the migratory experience. They encounter other mobilities, other circulations, and other groups before which there is a need to think of oneself as migrating and circulating.

Does that mean that the border becomes a 'non-place' (Augé 1992) where spatial, cultural and social distances vanish? It certainly entails geographic proximity, and proximity of social spaces, but the border does not seem to be a 'non-place'. If its functionality makes a shared experience out of it, it may be because there are other borders within the formal border: identity boundaries that become resources from which the occupied space is organised. In this sense, for Haitians, the constructed and lived 'mobility fields' contribute to the creation of a feeling of belonging for the formerly settled and the newcomers. But the emergence of a certain shared 'identity' does not mean that there will not be confrontation with the new value system. It even reinforces the difficulties encountered in relation to the irregularities within which identity representation also takes shape. We will now consider the various modalities through which Haitian identity is experienced that impact the migratory experience and the experience of others that they encounter during their travels between Suriname and French Guiana. The question of identity construction allows us to look at the issue of the border in a new light. We have so far examined how migration and mobilities are influenced by state borders, that is how 
they and their permeability impact on migratory routes, and social and economic borders that exist in the places where migrants settle. Yet, migrants are not only 'border crossers', but are also 'boundary builders'. They build identity boundaries shaping a new collective entity taken out of a whole, the one of the 'other strangers', being, in the context of the West of French Guiana, the Businenge groups.

More than thirty years of migration have reinforced the socio-cultural heterogeneity of French Guianese society. Demographic growth is partly linked to these migratory movements that also deeply affect inter-group relationships. In this context, signs of recognition and of belonging to the group go with the idea of 'community', being a support and a resource taking part in the individual and collective relationships. The idea of a common and unique 'origin' that merges culture and nationality, distinguishes each group from the other. As is common in the daily practices of identity construction, the notion of an origin, imposed from the outside, also enters into the processes of selfconstruction of the migrants. These appear as many elaborations marked by the imposition and re-appropriation of acts of identity and naming coming from others (an 'exo-identification'). Thus, in French Guiana, Haitians identify themselves as a singular entity and are characterised by the idea of Haitian nationality. It is a matter of belonging to a 'Haitian nation'. This elaboration is thought of as a merging of other identifications that find a coherence according to the levels of interaction in which they arise. First, within the group itself, is the feeling of belonging to a local and localised identity. National identity is expressed in terms of regional belonging: one is Haitian from Leogane, from Saint-Louis-du-Sud, from Cabaret, etc. Then, without however contradicting the territorial label, Haitian identity acquires a historical dimension: Haitians and Haiti meet in the past. This dimension of the 'nation', considered in its historical continuity, is what is invested in migration. It is from that perspective that the Haitian reference is called up in social exchanges to be asserted as a 'community' within society. The sharing of this 'identity' does not prevent one from valuing invisibility outside the group and the inhabited places where this identification operates. The 'origin' is not—so far-developed as a communitarian identity discourse; it does not lead to collective speech. In general, in the relationships experienced with the different groups, it is only when xenophobia is denounced, when hostility is felt, when extraneity is strongly 
felt, that an 'identity' is expressed. This point comes as a reminder, if needed, that identifications cannot be understood outside the social context in which and by which they are created. We should also keep in mind that the different levels of identifications can take on differentiated forms that force us to abandon a paradigm of identifying migrants as a coherent and stable unit (Laëthier 2011a).

In western French Guiana, Haitians interact with Creoles, Metropolitans, Hmongs, and Maroons locally referred to as 'Businenge'. Yet, 'Haitian identity/ alterity' is most strongly articulated in relation to 'other strangers' and first of all with reference to members of the different Maroon communities who are locally often cast as originating from Suriname despite the fact that some of them have been part of the French Guianese landscape for a long time. The reason for this is that in Saint-Laurent-du-Maroni and in Mana, unlike what was experienced in Suriname, Haitians generally live in the same neighbourhoods as Maroons. Haitians and Maroons do not live in the same houses or larger compounds and generally assert that their relationships are 'good' and that there are no 'major problems'. However, it is noticeable that although they live in close proximity, they never really mix with each other socially. It is said that those who have problems are "[Haitian] men who go looking for a woman among the Bosh" and that anyway, there is no "nation more racist than the Haitian one". However, social relationships produce an ethnicised mode of relationship, and from this point of view, boundaries do exist. For instance, Haitians re-appropriate cultural stereotypes about Maroons-stereotypes obeying the same logic as those stigmatising Haitians - that cast their language in a pejorative manner, as gibberish. The pejorative expression takitaki is currently used to refer to the English-lexified creoles ideologically linked to Maroons. Following the same logic, some migrants assert that they will send their children to a private school as soon as possible in order to minimise contact with so many 'Bosh' and with their language. In a similar vein, some migrants justify their move to French Guiana by emphasising that they want to send their child to a French and French-speaking school. ${ }^{17}$

17 Parents have great respect for school and school titles are invested with great value. Prospects of upward mobility and prestige of the diploma are strong among people, who, when they could go to school, had to leave the educational system prematurely. 
Although Haitians know that there are several 'Bosh nations', as they call them, they rarely differentiate them because they do not perceive differences between them. Only the term 'Saramaka' states a distinction. However, when Haitians talk about 'Saramaka', they mostly use the term to designate boatmen and to refer to a part of Suriname, the Saramacca District, where they rarely go. Indeed for them, Suriname is divided into Albina, Foto and the 'Saramaka country' which refers to all the rest of the territory. 'Saramaka' country appears to be what is called in Haiti 'the outside country' (peyi andeyò), that is to say, the rural world, the world of the farmers which is highly stigmatised. ${ }^{18}$ When Haitians define Maroons as nèg ki sòt nan bwa, literally 'Negroes from the woods', they are not referring to their knowledge of the historical process of marronage or to their knowledge of the terms Bush Negroes/Bosnegers. They are expressing that 'Bosh' are 'people from the outside country'. But they soon remind us that, in the country they left, they are the moun andeyo 'people from outside country'.

It is known that stressing how far on the 'outside' those constructed as 'other' are, leads to the elaboration of boundaries within which to differentiate oneself. But the process takes on a singular aspect here. Differentiation involves another construction: a construction that specifies a relationship established with 'France', considered as 'nation' on one hand, and as 'State', on the other hand. The construction of a 'Haitian identity/alterity' operates at a collective level and joins the process of national identification.

Haitians often feel that they have greater rights to French residency papers than Maroons because Haiti has historical ties with France and also because French is one of the official languages of Haiti. ${ }^{19}$ By contrast, Suriname, the imagined home of Maroons, only shares physical or geographical proximity with France, making Maroons 'less French' than Haitians. Thus apprehensive feelings towards the colonial period and the sufferings related to it-denounced in other situations - are momentarily backgrounded. The telling of a memory, through which the migrants appear to be representative of the only nation of the Caribbean that claimed its freedom and gained its

18 In Haiti, as early as the nineteenth century, social relationships were structured by stigmatising the rural world, viewed as a sign of inferiority.

19 Among the migrants, Haitian Creole is by far the most widely-spoken language. Even if French and French Guianese Creole appear in their language repertoire, they are not practised to the same extent as Haitian Creole. With a family member or a fellow citizen, regardless of age, date of arrival or professions, it is Haitian Creole that is typically spoken. (Laëthier 2007). 
independence is backgrounded. However, the enhancement of the Haitian past, that is found in the speech of many migrants, sometimes in an explicit and incisive form condensed in the following sentence: "All black nations await something from us for we are the first people to have become independent", does not appear. The proximity to France, as stated here, can also be used to denounce the current precarious social and political situation of Haiti because of the independence that was taken 'without thinking', and in addition, doing 'magic'. This construction of the past and the functions that it comes to serve in migration fuels the different discussions around an eventual independence of French Guiana and the treatment of foreigners that would ensue. For some, however, this reconstruction of the past reinforces the idea that Haitians would be forced out of French Guiana if it were to become independent, precisely because of the great proximity of Haitians with 'France'. For others, it would not be foreigners like them who would be expelled.

The discursive delimitation of a boundary (Poutignat and Streiff-Fenrat 1995; Barth 1969) that is set within the common extraneity, also evokes the question of papers and the possibility of regularisation both linked to the important contribution that Haitians are making to the economic development of French Guiana. The economic dimension is invoked in order to prove that farmers play an important role in the development of the department. While Haitians acknowledge that other social groups also contribute to the development of French Guiana, they cast themselves as "the great workers of French Guiana". This dovetails with their purported respect for and knowledge of "French customs in such speeches, but expresses a lack of understanding of the precarious administrative and social situation of Haitians in French Guiana. One of the arguments aimed at denouncing the Haitian presence that is frequently put forward by Creoles and Metropolitan French people in contact with them, is the fact that they are mostly responsible for the ecological degradation of the department because they practice intense slash-and-burn agriculture.

Other 'moral' and cultural criteria can also reinforce the border. Take, for instance, comments about the incidents of violence attributed to Maroons. Among Haitians, their presence is indeed seen as destabilising because they are presumably linked to increasing crime and violence, and the frequent use of 'bad magic'. The latter issue in turn is often used among French Guianese Creoles to rally against Haitians. This argument underlines Haitians' frustration with French authorities which are reluctant to help them obtain a residence permit.

These identity positionings should not, however, be overestimated. On the one hand, as they now appear, the relationships and the representations that 
rule them are also linked to the limited number of interactions with the everyday life of the "others" such as metropolitan French people, Maroons etc. There is no real relating of the groups in situations allowing a strong inter-subjective engagement. Interactions are mostly brief and superficial and thus do not contradict the described positionings. Let us consider the case of 'Bosh taxis', illegal taxis that are used in the absence of proper public transport, which Haitians living along $C D 8$ and $C D 10$ make frequent use of. These taxis allow them to go to Saint-Laurent-du-Maroni or to the town of Mana to 'conduct business' or to attend worship services. They allow them to connect with others. Between them, the Surinamese route appears sometimes as a shared migratory route. Sometimes, it is the fact that they are both extraneous to this land that constitutes a common shared experience. It demonstrates all the ambiguity of their relationship.

Besides, enhancement of the Haitian past condensed in the experience of Independence appears as an argument playing contradictory roles. Thus, faced with the political and social situation in which Haiti finds itself nowadays, the reading of the past is reconsidered as a regret that Haitians, unlike Maroons, do not manage collectively. Thus, it is stated that among Haitians, there are no "chiefs as among Bosh or [Amer] Indians" or also that work and its productions are not shared. The societal individualism assumed here is denounced and appears as a negative characteristic of the 'Haitian nation' since its Independence. As shown by Jolivet (1997), this image contradicts the view that French Guianese Creoles have of Haitians - and of Maroons; they assume that the latter are close-knit communities and regret that this sense of community has been lost among French Guianese Creoles. Could this issue not also serve to highlight the proximity of Haitians with French Guianese Creoles and not simply just with 'France'?

The views presented here are characteristic of the adult first generation of Haitian immigrants to French Guiana (and Suriname). Data recently collected among younger people of Haitian extraction who have been only or primarily socialised in French Guiana suggest that they do not have the same identity reference as their parents did. Generally speaking, young people born in French Guiana try to distance themselves from the majority of practices and values that they associate with their parents' culture and with the past in Haiti. They do this by claiming to be/identifying as Guyanais 'French Guianese' or Haitian-born in French Guiana.

Finally, in a multicultural context where, for most of the groups present, the colonial relationship shapes the question of origins, let us keep in mind that the dynamic dimension of identification opens the way to the possibility of establishing a distance but also a proximity between the groups. From this 
last point of view, the question arises about the existence of identifications whose core would become a historical conscience, a conscience of the originality marked by the act of resisting: enhancement of the freedom conquered by fights for independence in the case of the Haitians, and by marronage as a means to conquer autonomy in the case of Maroons. 